\title{
The Effect of Interviewer Image in a Virtual-World Survey
}

Joe Murphy, Elizabeth Dean, Sarah Cook, and Michael Keating

December 2010 


\section{About the Authors}

Joe Murphy, MA, is a survey methodologist at RTI who researches data quality and innovations in survey techniques and procedures.

Elizabeth Dean, MA, is a survey methodologist at RTI who designs survey instruments and qualitative assessments, including usability testing and cognitive interviewing

Sarah Cook, MA, is survey methodologist at RTI specializing in the review and refinement of questionnaires and materials.

Michael Keating, MA, is a survey specialist at RTI who manages survey data collection and quality control efforts.
RTI Press publication RR-0014-1012

This PDF document was made available from www.rti.org as a public service of RTI International. More information about RTI Press can be found at http://www.rti.org/rtipress.

RTI International is an independent, nonprofit research organization dedicated to improving the human condition by turning knowledge into practice. The RTI Press mission is to disseminate information about RTI research, analytic tools, and technical expertise to a national and international audience. RTI Press publications are peer-reviewed by at least two independent substantive experts and one or more Press editors.

\section{Suggested Citation}

Murphy, J., Dean, E., Cook, S., and Keating, M. (2010). The Effect of Interviewer Image in a Virtual-World Survey. RTI Press publication No. RR-0014-1012. Research Triangle Park, NC: RTI Press. Retrieved [date] from http://www.rti. org/rtipress.
This publication is part of the RTI Press Research Report series.

RTI International

3040 Cornwallis Road

PO Box 12194

Research Triangle Park, NC

27709-2194 USA

Tel: $\quad+1.919 .541 .6000$

Fax: $\quad+1.919 .541 .5985$

E-mail: rtipress@rti.org

Web site: www.rti.org
(C)2010 Research Triangle Institute. RTI International is a trade name of Research Triangle Institute.

All rights reserved. Please note that this document is copyrighted and credit must be provided to the authors and source of the document when you quote from it. You must not sell the document or make a profit from reproducing it.

doi:10.3768/rtipress.2010.rr.0014.1012

www.rti.org/rtipress 


\title{
The Effect of Interviewer Image in a Virtual-World Survey
}

Joe Murphy, Elizabeth Dean, Sarah Cook, and Michael Keating

$\begin{array}{lr}\text { Contents } & \\ \text { Introduction } & 2 \\ \quad \text { Interviewer Presence } & 2 \\ \quad \text { Interviewing Using Avatars } & 2 \\ \quad \text { Second Life } & 3 \\ \text { Methods } & 4 \\ \text { Findings } & 5 \\ \text { Discussion } & 7 \\ \text { References } & 8 \\ \text { Appendix } & 11\end{array}$

\begin{abstract}
When survey respondents are consciously or unconsciously influenced by the characteristics of the interviewer, bias in the survey estimates may result. The effects of interviewer characteristics such as gender and race on survey estimates have been considered previously, but isolating and experimentally manipulating a single interviewer characteristic has been infeasible. With the advent of online virtual worlds, it is now possible to conduct experiments focusing on individual physical interviewer characteristics. We conducted an exploratory study, surveying 60 individuals in Second Life, an online virtual-world community in which the respondent and interviewer were both represented as avatars - three-dimensional representations of real-life individuals. To explore the effect of interviewer appearance on reported health behaviors and attitudes, we randomly assigned half of the survey respondents to a "thin" interviewer and half to a "heavy" interviewer. The data suggest that those who reported to the heavy interviewer were less likely to say their own avatar was attractive, reported less frequent real-life exercise, and reported a higher real-life body mass index, although because of the small number of participants, we did not detect statistically significant differences. The findings suggest that interviewer appearance may have a biasing effect on reports in virtual-world surveys-and perhaps in real-world surveys. Despite the lack of statistically significant findings, the study illustrates the future potential, benefits, and challenges to surveying and conducting methodological research in a virtual world.
\end{abstract}




\section{Introduction}

\section{Interviewer Presence}

Survey researchers often employ interviewers to administer questionnaires in the field because they can build rapport and guide the respondent through the questionnaire. However, research has shown that interviewer presence may introduce error into survey estimates. Some respondents reportedly divulge lessthan-honest answers to sensitive questions when an interviewer is present, as in face-to-face interviews (Tourangeau \& Smith, 1996; Turner et al., 1998). Also, fixed interviewer attributes, such as race and gender, can influence respondent answers when asked about issues related to those attributes (Couper, 2008). When responses are influenced by interviewer characteristics, either consciously or unconsciously, survey estimates may be biased.

With the advent of telephone interviewing, the physical presence of an interviewer was eliminated, but less-than-candid reporting of sensitive information still occurred because respondents were still speaking directly to another person (de Leeuw \& van der Zouwen, 1988; Tourangeau \& Yan, 2007). To address the effect of bias due to the presence of an interviewer, researchers developed and employed modes such as audio computer-assisted selfinterviewing (ACASI), which replaces the interviewer with a recorded voice, allowing respondents to report on attitudes and behaviors subject to social desirability bias (Couper \& Rowe, 1996; Newman et al., 2002; Richman, Kiesler, Weisband, \& Drasgow, 1999).

Although this type of self-administration has benefits, the advantages of interviewer presence cannot be ignored. Respondents have been found to be more engaged and involved in the survey when an interviewer is employed than when one is not (Anderson, 2007; Walker, Sproull, \& Subramini, 1994). Moreover, an interviewer can reduce item nonresponse in ways and to an extent that a selfadministered survey cannot (de Leeuw, 1992), including reducing the number of "don't know" responses and refusals to respond (Dillman, 2000).

\section{Interviewing Using Avatars}

An emerging method that is relatively inexpensive and takes advantage of interviewer presence but with some level of social distance is interviewing using avatars. An avatar is a digital representation of a person controlled by an individual at a computer. Interaction takes place in virtual rooms or environments, and instead of conversing "in the flesh," users have their avatars speak, or "chat," with each other. Surveys using avatars as interviewers have the potential to combine the benefits of a physical interviewer's social presence with those that come with the distance of self-administered modes. This notion is supported by the "computers as social actors" or CASA paradigm, which states that people react to computers as social actors providing a social presence, not as inorganic machines (Fogg \& Nass, 1997; Nass, Moon, \& Green, 1997; Nass, Fogg, \& Moon, 1996; Nass, Moon, \& Carney, 1999). One experiment done by Walker, Sproull, and Subramini (1994) found that the features of the survey interface can simulate the presence of a social being. Their study asked participants questions on a computer using either a text display or a talking face (avatar). The avatar mode resulted in users spending more time interacting with the program and making fewer errors than those who used only a text interface. This finding suggests that respondents may perceive some personal presence through a virtual interviewer interaction, but not with the magnitude of a real interviewer and not enough to hinder truthful responses to sensitive questions. Using avatar interviewers in a virtual setting, as opposed to face-to-face, telephone, or self-administered modes, may help researchers obtain sensitive information accurately while still keeping the benefits of an interviewer's presence.

Another benefit of avatars is that they can be customized to the user's specifications and, therefore, provide an opportunity to control or study the effects of interviewer image, including race, gender, or physical appearance. For example, one can manipulate the body type of an avatar to be heavy or thin and discern the effect of interviewer size on survey response. According to Groves et al. (2004), respondents alter their reporting when observable traits of the interviewer are related to the questions 
being asked. An interviewer's race or perceived attractiveness has been found to influence not only the respondent's trust, but also the respondent's beliefs about what constitutes a desirable response (Krysan \& Couper, 2003; Davis \& Silver, 2003; Anderson, Silver, \& Abramson, 1988; Finkel, Couper, \& Steiger, 1991; Hatchet \& Schuman, 1976; Summers \& Hammonds, 1966). Kane and Macauley (1993) and Tourangeau et al. (2003) both found that the interviewer's gender can influence responses to questions about feminism. Some research has found that interactive voice recording respondents sometimes even stereotype the "interviewer" on the basis of the recorded voice's sex (Nass, Moon, \& Green, 1997; Sproull, Subramani, Kiesler, Walker, \& Waters, 1996).

\section{Second Life}

Although the effects of interviewer race and gender have been considered, interviewer body type has received little attention. In our culture, body type is often seen as a measure of attractiveness in that heavier body types are usually considered less attractive. There have been conflicting reports in the past few decades on whether attractiveness of a person affects perceived trustworthiness (see Darby \& Jeffers, 1988; Joseph, 1982). Regardless of trustworthiness, Cialdini and Trost (1998) report that people are more inclined to comply with the requests of someone whom they like or see as similar to themselves. Burger, Soroka, Gonzago, Murphy, \& Somervell (2001) also argue that greater perceived similarity would increase the likelihood of compliance with a person's request. Therefore, respondents assigned to a "heavier" interviewer should be more at ease reporting real-life body weight and physical activity levels honestly. This should be true even if they are not the socially acceptable answers because the person to whom they are reporting appears not to follow the social standards.

Our study examined the effect of interviewer size in Second Life-an online three-dimensional environment where users are termed "residents." With more than 15 million residents, Second Life is a popular example of an online environment designed like a massive multiplayer online game. Residents create the content of the world, including facilities, houses, landscapes, and businesses, and they design their own avatars to represent themselves. Residents' activities include communicating by means of text chat, voice chat, and instant messages; socializing and networking; buying and selling virtual goods and services with Second Life's own currency, "Linden dollars" (L\$); marketing real-life businesses and corporations; and engaging in education and distance learning. Although virtual worlds may have initially been embraced only by younger computer-savvy gamers and artists, their appeal continues to grow (Bainbridge, 2007). Compared with the general population, Second Life residents tend to be between the ages of 25 and 44, slightly more male, and well educated (The Social Research Foundation, 2008). However, an increase in popularity may be making Second Life residents more diverse and representative of the general population. With 124 million userhours logged in Quarter 1 of 2009-an increase of 42 percent since the previous year (Linden, 2009) Second Life represents a new means by which to reach specific populations and survey respondents. It also represents a new social landscape with new ways for individuals to express opinions and experience psychosocial interactions. Giving the user the ability to control the environment and context of survey interviews, Second Life presents an opportunity to conduct social research experiments in virtual worlds. We call data collection in virtual worlds such as Second Life "in-avatar interviewing."

To ascertain the feasibility and effects of in-avatar interviewing, as well as interviewer body type manipulation, we designed and conducted an exploratory survey on the topics of physical activity, health behavior, and self-perception in Second Life. These topics are of interest to health researchers, especially in light of the growing obesity epidemic in the United States (Dean, Cook, Keating, \& Murphy, 2009). We felt that manipulating the body type of the interviewer would produce similar effects on responses to those observed in past studies of interviewer race and gender when the questions were related to those attributes. Using a "heavier" interviewer may allow respondents to admit to less healthy behaviors because the interviewer's appearance could suggest that he or she also engages in less healthy behaviors. We believe that in real 
life many of the survey respondents may more closely resemble the heavy interviewer than the thin interviewer. We also believe participants are more likely to respond truthfully when they believe the avatar interviewer looks similar to themselves.

In our study, half the respondents interacted with a "heavy" interviewer, and half interacted with a "thin" interviewer. Whether respondents react differently to different interviewer body types may have implications for survey data in both virtual and real-world environments. We hypothesized that those reporting to the heavy interviewer would be more likely to report higher (possibly more truthful) real-life body measurements but would be less likely to consider themselves as overweight in the presence of the heavy interviewer. Moreover, we hypothesized that respondents reporting to the heavy interviewer would report less physical activity in real life than those reporting to a thin interviewer.

\section{Methods}

RTI International currently maintains a location in Second Life that was set up, in part, to explore the feasibility of conducting survey interviews in a virtual world and the methodological challenges and opportunities. The uniqueness of the chosen virtual world influenced our recruitment methods and our conduct of the interviews.

The questionnaire in this study consisted of 21 questions on a variety of topics, including health and exercise habits (see the Appendix). Most questions were closed ended, with the exception of a couple of questions on real-life height and weight. Health questions focused on self-perception of Second Life and real-life physical attractiveness and body size; exercise questions focused on the frequency and rigor of physical activity.

For this exploratory study, we had resources available to select a small sample of 60 respondents. To build the sample, we used two recruitment techniques that were successful in prior Second Life studies conducted by RTI. The first technique was to send messages to an RTI survey group created in Second Life for interested potential respondents. Avatars could join the group to learn about the survey opportunities at RTI. The second technique was to post a message in the classified section of the Second Life forum Web site. These two methods closely resemble real-life recruitment methods, by which an organization may, for example, post a recruitment advertisement in a newspaper. For the interview, we offered respondents $\mathrm{L} \$ 1,000$, which exchanges with United States currency at approximately $\$ 4.00$.

The process for interviewing respondents included many procedures unique to virtual worlds. If a potential respondent was interested in participating in the study, we asked him or her to contact our data collection manager via Second Life instant messaging, which does not require that both users be online to send messages. If a respondent tried to contact RTI while our data collection avatar was off-line, we would receive the message during our next log-in and respond. Second Life instant messaging made setting appointments easy.

We only interviewed respondents who currently lived in the United States because of the survey's focus on health and behavior for this population. Before an interview was conducted, our data collection manager screened each potential respondent by asking, "Do you currently live in the United States?". If a respondent was eligible to participate, then we sent the Second Life URL (SLURL) of the virtual RTI facility (Figure 1) in Second Life to the respondent. By clicking on the SLURL, the respondent could teleport to our facilities, which simplified the logistics

\section{Figure 1. Virtual RTI facility}

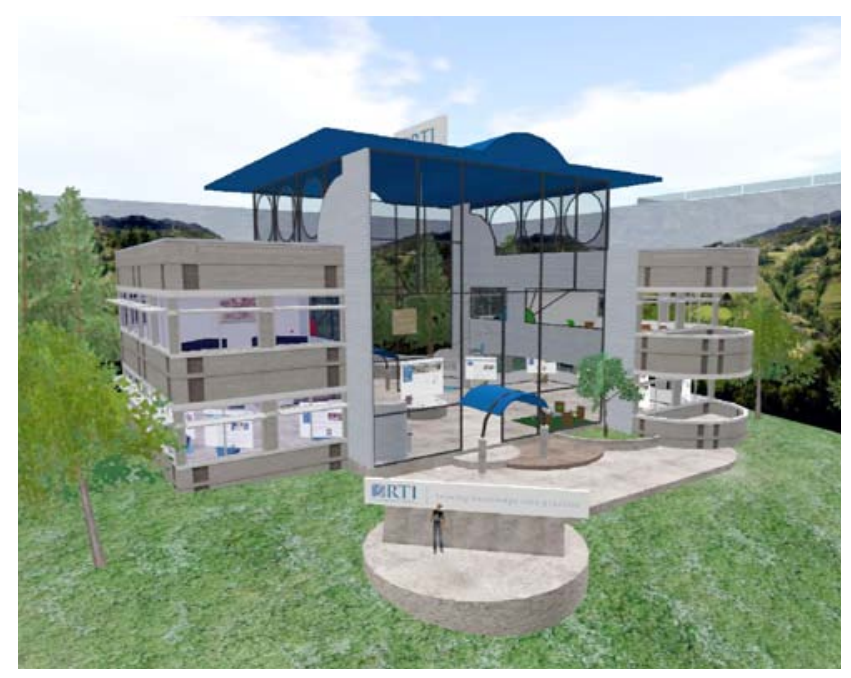


of travel to RTI for the interview. On the respondent's arrival at the virtual facility, our data collection manager greeted him or her in the lobby.

After welcoming each respondent, the data collection manager instructed respondents on how to access a private interviewing room. The RTI facility had four secure rooms that were pass-code protected; in each of these rooms an interviewer was waiting. The security of these rooms increased the privacy of the interview for respondents. The windows of these rooms were equipped with shades for even more privacy. Upon arrival in the room, the interviewer obtained the respondent's consent by handing the respondent a digital note card containing the consent information approved by RTI's Institutional Review Board. After obtaining consent, the interviewer began the interview.

For these interviews, each respondent was randomly assigned to either the heavy or thin interviewer (Figure 2). To conduct the interview, our staff used the Second Life instant message system. One of the advantages of using this system was that the entire chat conversation was automatically transcribed and could be accessed for later reference. On a few occasions, one of our interviewers forgot to ask the respondent one of the survey questions. We asked this interviewer to recontact these respondents by means of the Second Life instant message tool. Because it was not necessary for two avatars to be online at the same time to communicate through instant messaging, a respondent could respond to the missed question at his or her convenience, which made recontacting respondents and eliciting the missing response efficient. The interview length varied but,

\section{Figure 2. Images of heavy and thin interviewers}

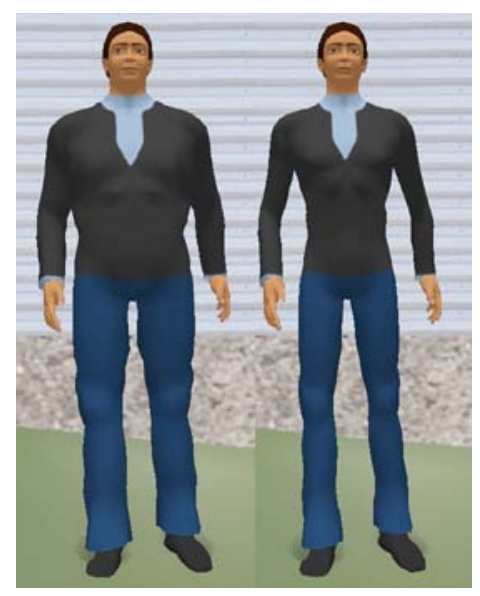

on average, took about 10 minutes. After an interview was completed, the chat files were cleaned and then saved as text files on RTI's secure internal servers. From there we extracted the data for analysis.

The measures included for analysis concerned the respondent-avatar's impressions of his or her own real-life and virtual characteristics and activities, as well as real-life body mass index (BMI). BMI was calculated from reported real-life weight and height with the standard formula: $\mathrm{BMI}=$ (weight in pounds) $\times 703$ / (height in inches squared). A BMI of 18.5 to 24.9 is considered to be in the healthy range, 25 to 29.9 is considered overweight, and 30 or more is considered obese (National Institutes of Health, 2010).

\section{Findings}

If interviewer size had no effect, we would expect the absolute point difference in each measure to be minimal. We report the key survey measures by interviewer size (Table 1). Although this exploratory study was too small to detect significant differences in the included measures, some absolute point differences were large, suggesting a larger scale study may find significance in the differences. Among those interviewed by a thin avatar, 77 percent thought their personal avatar was very attractive or attractive, as opposed to only 60 percent among those interviewed by a heavy interviewer. Avatar exercise level was lower among those reporting to a thin interviewer (50 percent exercised in Second Life at least once a week) than among those reporting to a heavy interviewer (63 percent). We found an opposite trend with self-reported real-life exercise levels: A full 77 percent reported real-life exercise frequency of at least once a week when the interviewer was thin, as opposed to 63 percent when the interviewer was heavy. Reported calculated real-life BMI was lower among those responding to the thin interviewer (41 percent with $\mathrm{BMI} \geq 25$ ) than among those responding to the heavy interviewer (57 percent). As would be expected, avatar size appeared to have almost no correlation with age and gender, with an absolute difference of only 3 percentage points between the thin and heavy interviewer groups on both measures. 


\section{Table 1. Key survey measures, by interviewer size}

\begin{tabular}{|c|c|c|c|c|}
\hline \multirow[b]{2}{*}{ Measure } & \multicolumn{2}{|c|}{ Interviewer Size } & \multirow[b]{2}{*}{$\begin{array}{l}\text { Absolute Point } \\
\text { Difference }\end{array}$} & \multirow[b]{2}{*}{$\begin{array}{c}\text { Chi-Square } \\
p \text { Value }\end{array}$} \\
\hline & $\begin{array}{c}\text { Thin } \\
(n=30)\end{array}$ & $\begin{array}{c}\text { Heavy } \\
(n=30)\end{array}$ & & \\
\hline Considers own avatar very attractive or attractive & $77 \%$ & $60 \%$ & 17 & .17 \\
\hline Considers own avatar fat or about average & $60 \%$ & $67 \%$ & 7 & .59 \\
\hline Reports that own avatar exercises at least once a week & $50 \%$ & $63 \%$ & 13 & .30 \\
\hline Considers own real-life size obese or overweight & $33 \%$ & $33 \%$ & 0 & 1.00 \\
\hline Reports real-life exercise at least once a week & $77 \%$ & $63 \%$ & 14 & .26 \\
\hline Reports a real-life $\mathrm{BMI} \geq 25$ & $41 \%$ & $57 \%$ & 16 & .23 \\
\hline Reports a real-life age $18-24$ & $30 \%$ & $33 \%$ & 3 & .78 \\
\hline Reports real-life gender as male & $40 \%$ & $43 \%$ & 3 & .79 \\
\hline
\end{tabular}

$\mathrm{BMI}=$ body mass index.

Note: Three cases with outlier values of $\mathrm{BMI}<12$ or $>40$ were removed because of questionable data.

To further explore relations among the key measures and determine the role of interviewer type in this study, we fitted several multiple logistic regression models estimating key measures as a function of interviewer size and other key measures as controls. Using backward selection, we retained variables significant at the $.15 p$ value. Table 2 presents selected strong odds ratios by measure. We included odds ratios rather than parameter estimates because odds ratios afforded a more straightforward interpretation.
The logistic regression models show that the odds of reporting attractiveness with a heavy interviewer were 0.36 of those with a thin interviewer. Similarly, the odds of reporting frequent exercise to a heavy interviewer were only 0.37 of the same report to a thin interviewer. Regarding the effect of interviewer size on BMI, the odds of reporting BMI $\geq 25$ to a heavy interviewer were 2.65 that of reporting an overweight BMI to a thin interviewer. These odds ratios are strong but do not reach statistical significance because of the small sample size.

\begin{tabular}{|c|c|c|c|c|}
\hline $\begin{array}{l}\text { Model } \\
\text { Predicting }\end{array}$ & Predictor & $\begin{array}{l}\text { Odds } \\
\text { Ratio }\end{array}$ & $\begin{array}{l}95 \% \text { Confidence } \\
\text { Interval }\end{array}$ & $\begin{array}{c}\text { Parameter } \\
p \text { Value }\end{array}$ \\
\hline \multirow[t]{3}{*}{ Considers own avatar very attractive or attractive } & Heavy interviewer & 0.36 & $0.10-1.31$ & .12 \\
\hline & Male & 0.12 & $0.03-0.55$ & .00 \\
\hline & $\mathrm{BMI} \geq 25$ & 4.11 & $0.99-17.11$ & .05 \\
\hline Considers own avatar fat or about average & None & - & - & - \\
\hline Reports that own avatar exercises at least once a week & Aged $18-24$ years & 0.25 & $0.08-0.82$ & .02 \\
\hline Considers own real-life size obese or overweight & $\mathrm{BMI} \geq 25$ & 18.00 & $3.56-90.92$ & .00 \\
\hline \multirow[t]{3}{*}{ Reports exercising in real life at least once a week } & Heavy interviewer & 0.37 & $0.10-1.32$ & .13 \\
\hline & Aged $18-24$ years & 3.74 & $0.82-17.13$ & .09 \\
\hline & $\mathrm{BMI} \geq 25$ & 3.23 & $0.86-12.20$ & .08 \\
\hline \multirow[t]{4}{*}{ Reports a real-life $\mathrm{BMI} \geq 25$} & Heavy interviewer & 2.65 & $0.78-9.01$ & .12 \\
\hline & Real-life exercise & 2.84 & $0.72-11.27$ & .14 \\
\hline & Male & 2.66 & $0.78-9.00$ & .12 \\
\hline & Aged $18-24$ years & 0.17 & $0.04-0.69$ & .01 \\
\hline
\end{tabular}

$\mathrm{BMI}=$ body mass index.

Note: Three cases with outlier values of $\mathrm{BMI}<12$ or $>40$ were removed because of questionable data. 


\section{Discussion}

This study illustrates that survey research in a virtual world is feasible to conduct and provides opportunities for investigating methodological issues such as the effects of interviewer characteristics. We were able to quickly and inexpensively recruit survey participants in Second Life, meet with them at our virtual research facility, and complete interviews using heavy and thin versions of otherwise identical survey interviewers. From this experience, we found conducting surveys in Second Life to be a viable option from an operational standpoint.

Regarding the interviewer image experiment, when a heavy avatar conducted the interview, we observed the following patterns:

- respondents were less likely to say their personal avatar was attractive,

- respondents reported less frequent real-life exercise, and

- respondents reported a higher real-life BMI.

If heavier interviewers obtain lower reports of real-life physical activity and higher real-life BMI, this could have implications for researchers' understanding of respondent and interviewer interactions in both virtual and real-world surveys.

We must qualify any conclusions from these results with an observation of the study's limitations. This was an exploratory study with a small sample size. Although we detected substantial differences between the heavy and thin interviewers, none of the findings qualify as statistically significant. Furthermore, the virtual-world environment is artificially constructed and is a social and gaming environment that may appeal more to a specific subset of the populationindividuals with a keen interest in overcoming the learning curve of participation or who have an interest in technology or visual design. Recruiting survey respondents from outside the virtual world to participate in a survey in Second Life would be a logistical challenge, though we hope to pursue this possibility. At present, the results of this exploratory research lack a real-world validation. For instance, one easily discernible feature of the virtual-world environment where users can pick and choose their avatars' physical characteristics is that most avatars tend to be thin. A heavyset avatar is more of a novelty, whereas in the United States, over 50 percent of the population is overweight or obese. These facts of conducting body image-related research in Second Life limit any real-world conclusions that can be made.

Given the limitations mentioned above, we speculate at this point about the social and cognitive processes that may be influencing this apparent pattern in our results. A heavier interviewer may be encouraging reporting of less healthy behavior and higher BMI through visual cues about what is the norm (a larger body size, associated with less physical activity), with the interviewer subtly conveying through appearance what is appropriate. Higher BMI and less physical activity may be considered more socially acceptable in the presence of a heavier interviewer and may have resulted in responses that were more honest. The impact of interviewer size on social acceptability is especially interesting when one considers the decreased reporting of avatar attractiveness when the interviewer was heavy. Perhaps general social pressure persists to report less personal attractiveness in the presence of an interviewer with a less socially desirable body type. Alternatively, the respondent's trust in the interviewer may be higher when the interviewer's avatar is heavier, resulting in responses that are candid. In Second Life, body types are idealized, so avatars are most often thin and physically fit. Perhaps a heavier avatar suggests the interviewer is more "human."

Future research with a larger sample may clarify our results. It is reasonable to expect that a larger study would generate statistically significant results, given the strong odds ratios. We look forward to replicating the study in continuing exploration of survey research in Second Life. A larger study should also consider collecting more detail on the respondent's real-life and Second Life physical traits. Collection of avatar paradata (such as independent coding and assessment of body type and other physical traits) and an analysis of body idealization among avatars in Second Life would be beneficial to understanding these preliminary results. A follow-up with respondents in real life could gauge the relationship (if one exists) between their Second Life body type and their real- 
life characteristics. Further studies in the virtual world could examine probable causes of the effect of the interviewer, if one is observed. If more conclusive results are found, the implications for real-world surveys should be addressed. If the interviewer's body type affects survey response, procedures for precisely identifying and controlling the effect should be developed. More generally, more work should be undertaken to hypothesize and test social science theories in virtual worlds like Second Life whenever testing in the real world may prove difficult or impossible. Although virtual worlds may currently be used more frequently by specific subpopulations, their appeal continues to grow. Virtual worlds are pervasive in the current web 2.0 environment-not just Second Life, but other extremely popular online spaces like World of Warcraft and Farmville for adults and Club Penguin and Nickelodeon Club for children-and may represent a dominant communication mode for friendships and social networking in the future. Furthermore, although virtual worlds are currently mostly popular with tech-savvy early adopters, these spaces offer rich environments in which to observe and measure social behavior.

\section{References}

Anderson, B., Silver, B., \& Abramson, P. (1988). The effects of the race of the interviewer on racerelated attitudes to black respondents in SRC/ CPS national election surveys. Public Opinion Quarterly, 52, 289-324.

Anderson, A. H. (2007). Video-mediated interactions and surveys. In F. G. Conrad \& M. F. Schober (Eds.), Envisioning the survey interview of the future (pp. 95-118). Hoboken, NJ: John Wiley \& Sons, Inc.

Bainbridge, W. S. (2007). The scientific research potential of virtual worlds. Science, 317(5837), 472-476.

Burger, J. M., Soroka, S., Gonzago, K., Murphy, E., \& Somervell, E. (2001). The effect of fleeting attraction on compliance to requests. Personality and Social Psychology Bulletin, 27, 1578-1586.

Cialdini, R. B., \& Trost, M. R. (1998). Social influence: Social norms, conformity, and compliance. In D. T. Gilbert, S. T. Fiske, \& G. Lindzey (Eds.), The handbook of social psychology (4th ed., pp. 151192). New York: McGraw-Hill.

Couper, M. P. (2007). Technology and the survey interview/questionnaire. In F. G. Conrad \& M. F. Schober (Eds.), Envisioning the survey interview of the future (pp. 58-76). Hoboken, NJ: John Wiley \& Sons, Inc.
Couper, M. P., \& Rowe, B. (1996). Evaluation of a computer assisted self-interview component in a computer-assisted personal interview survey. Public Opinion Quarterly, 60, 89-107.

Darby, B. W., \& Jeffers, D. (1988). The effects of defendant and juror attractiveness on simulated courtroom trial decisions. Social Behavior and Personality, 16(1), 39-50.

Davis, D., \& Silver, B. (2003). Stereotype threat and race of interviewer effects in a survey on political knowledge. American Journal of Political Science, 47(1), 33-45.

De Leeuw, E. D. (1992). Data quality in mail, telephone and face to face surveys. Amsterdam: T.T. Publikaties.

De Leeuw, E. D., \& van der Zouwen, J. (1988). Data quality in telephone and face-to-face surveys: A comparative meta-analysis. In R. Groves, P. P. Biemer, L. E. Lyberg, J. T. Massey, W. L. Nicholls, \& J. Waksberg (Eds.), Telephone survey methodology. New York: Wiley.

Dean, E. F., Cook, S. L., Keating, M. D., \& Murphy, J. J. (2009). Does this avatar make me look fat? Obesity and interviewing in Second Life. Journal of Virtual Worlds Research, 2(2). Retrieved from http://jvwresearch.org/

Dillman, D. A. (2000). Mail and Internet surveys: The tailored design method. New York: Wiley. 
Finkel, S., Guterbock, T., \& Borg, M. (1991). Race of interviewer effects in a pre-election poll: Virginia 1989. Public Opinion Quarterly, 55, 313-330.

Fogg, B. J., \& Nass, C. (1997). Silicon sycophants: The effects of computers that flatter. International Journal of Human-Computer Studies, 46(5), 551-561.

Groves, R., Fowler, F., Couper, M., Lepkowski, J., Singer, E., \& Tourangeau, R. (2004). Survey methodology. Hoboken, NJ: Wiley.

Hatchett, S., \& Schuman, H. (1976). White respondents and race-of-interviewer effects. Public Opinion Quarterly, 39(4), 523-528.

Joseph, W. B. (1982). The credibility of physically attractive communicators: A review. Journal of Advertising, 11(3), 15-24.

Kane, E. W., \& Macaulay, L. J. (1993). Interviewer gender and gender attitudes. Public Opinion Quarterly, 57, 1-28.

Krysan, M., \& Couper, M. P. (2003). Race in the live and the virtual interview: Racial deference, social desirability, and activation effect in attitude surveys. Social Psychology Quarterly, 66(4), 364-383.

Linden, T. (2009). The Second Life economy-First quarter 2009 in detail. Retrieved from https:// blogs.secondlife.com/community/features/ blog/2009/04/16/the-second-life-economy--firstquarter-2009-in-detail

Nass, C., Fogg, B. J., \& Moon, Y. (1996). Can computers be teammates? International Journal of Human-Computer Studies, 45(6), 669-678.

Nass, C., Moon, Y., \& Carney, P. (1999). Are people polite to computers? Responses to computerbased interviewing systems. Journal of Applied Social Psychology, 29(5): 1093-1109.

Nass, C., Moon, Y., \& Green, N. (1997). Are computers gender-neutral? Gender stereotypic responses to computers. Journal of Applied Social Psychology, 27(10), 864-876.
National Institutes of Health. (2010). Weight and waist measurement: Tools for adults. Weightcontrol Information Network. Retrieved from http://win.niddk.nih.gov/publications/tools. htm\#bodymassindex

Newman, J. C., Des Jarlais, D. C., Turner, C. F., Gribble, J., Cooley, P., \& Paone, D. (2002). The differential effects of face-to-face and computer interview modes. American Journal of Public Health, 92(2), 294-297.

Richman, W. L., Kiesler, S., Weisband, S., \& Drasgow, F. (1999). A meta-analytic study of social desirability distortion in computer-administered questionnaires, traditional questionnaires, and interviews. Journal of Applied Psychology, 84, 754-775.

The Social Research Foundation. (2008). 2008 Second Life survey. Retrieved from http://www.socialresearchfoundation.org/report /index_files/annual-survey.pdf

Sproull, L., Subramani, M., Kiesler, S., Walker., J. H., \& Waters, K. (1996). When the interface is a face. Human-Computer Interaction, 11(2), 97-124.

Summers, G. F., \& Hammonds, A. D. (1966). Effect of racial characteristics of investigator on selfenumerated responses to a Negro prejudice scale. Social Forces, 44, 515-518.

Tourangeau, R., Couper, M. P., \& Steiger, D. M. (2003). Humanizing self-administered surveys: Experiments on social presence in Web and IVR surveys. Computers in Human Behavior, 19(1), $1-24$.

Tourangeau, R., \& Smith, T. W. (1996). Asking sensitive questions: The impact of data collection mode, question format and question context. Public Opinion Quarterly, 60, 275-304.

Tourangeau, R. \& Yan, T. (2007). Sensitive questions in surveys. Psychological Bulletin, 133(5), 859-883. 
Turner, C. F., Forsyth, B. H., O’Reilly, J. M., Cooley, P. C., Smith, T. K., Rogers, S. M., \& Miller, H. G. (1998). Automated self-interviewing and the survey measurement of sensitive behaviors. In M. P. Couper, R. P. Baker, J. Bethlehem, C. Z. F. Clark, J. Martin, W. L. Nichols II, \& J. M. O'Reilly (Eds.), Computer assisted survey information collection (pp. 455-474). New York: Wiley and Sons.
Walker, J. H., Sproull, L., \& Subramani, R. (1994, April). Using a human face in an interface. Proceedings of the SIGCHI Conference on Human Factors in Computing Systems: Celebrating Interdependence (pp. 85-91). Boston, MA. 


\section{Appendix}

\section{Survey Questions}

\section{1) How did you learn about this survey?}

$1=$ SL classifieds;

2 = SL Herald classified ad;

3 = Ad in Mercury Sapphire Mall;

$4=$ SL forum post;

$5=$ Another avatar told me about it

$6=$ Other (specify)

\section{2) When answering these first questions, please} think about your Second Life avatar's identity.

How would you describe your SL avatar? Would you say very attractive, attractive, about average, unattractive, or very unattractive?

$1=$ Very attractive

$2=$ Attractive

$3=$ About average

$4=$ Unattractive

$5=$ Very unattractive

3) Do you think your avatar's body shape is fat, thin, or about average?

$1=$ Fat

$2=$ Thin

$3=$ About average

4) Do you consider your avatar to be tall, short, or about average?

$1=$ Tall

$2=$ Short

$3=$ About average
5) How often does your avatar participate in vigorous or moderate physical or leisure activitiesfor example running, playing a sport, or dancing?

Would you say at least once a week, occasionally, but less than once a week, or never?

$1=$ At least once a week

$2=$ Occasionally, but less than once a week

$3=$ Never

6) For the remaining questions, please think about your real life $(\mathrm{RL})$ identity.

How would you describe your appearance in RL? Would you say very attractive, attractive, about average, unattractive, or very unattractive?

$1=$ Very attractive

$2=$ Attractive

$3=$ About average

$4=$ Unattractive

$5=$ Very unattractive

7) In RL, how tall are you without shoes?

8) In RL, how much do you weigh without shoes?

9) In RL, do you consider yourself obese, overweight, underweight, or just about right?

(If you are currently pregnant, what did you consider yourself to be before you were pregnant?)

$1=$ Obese

$2=$ Overweight

$3=$ Underweight

$4=$ About right

10) During the past 12 months have you tried to lose weight in RL? 
11) The next questions are about physical activities that you do in real life, for example, exercise, sports, or physically active hobbies.

In RL, how often do you do light or moderate physical activities for at least 10 minutes? (Light or moderate activities cause only light sweating or a slight to moderate increase in breathing or heart rate.)

IF NECESSARY, PROMPT WITH: How many times per day, per week, per month, or per year do you do these activities?

12) In RL, how often do you do vigorous physical activities for at least $\mathbf{1 0}$ minutes? (Vigorous activities cause heavy sweating or large increases in breathing or heart rate.)

IF NECESSARY, PROMPT WITH: How many times per day, per week, per month, or per year do you do these activities?

These next few questions are about how you make phone calls.

13) Do you use Skype to place phone calls?

$1=$ Yes

$2=$ No

$3=$ Don't know what Skype is

14) Do you have a cell phone in RL?

$1=$ Yes

$2=$ No (skip to Q16)

15) Which of the following best describes your household in RL: Cell phone only or both a cell phone and a land line?

$1=$ Cell phone only (skip to Q17)

$2=$ Both a cell phone and a land line (skip to Q17)

16) Which of the following best describes your household in RL: Land line telephone only or no cell phone or land line?

$1=$ Land line telephone only

$2=$ No cell phone or land line
Now I want to know a little bit more about you.

17) How old are you in RL?

$1=18-24$

$2=25-34$

$3=35-44$

$4=45-54$

$5=55-64$

$6=65+$

18) Are you male or female in RL?

$1=$ Male

$2=$ Female

\section{9) Which group best describes you in RL?}

Are you white, Black or African American, American Indian or Native American, Asian or Pacific Islander, Hispanic or Latino, or something else?

$1=$ White

$2=$ Black or African American

$3=$ American Indian or Native American

$4=$ Asian or Pacific Islander

$5=$ Hispanic or Latino

$6=$ Other

20) What is the highest level of education you have completed in RL?

$1=$ Did not finish high school

$2=$ High school or ged

3 = Some college or two-year degree

$4=$ College graduate

5 = Post graduate degree (master's, doctorate, professional degree, etc.)

21) That is the end of our questions. Thank you for your time!

We would like to keep your avatar name on record in case there are other research opportunities. May we keep your avatar name?

$1=$ Yes

$2=\mathrm{No}$ 


\section{Acknowledgments}

This research was funded by an RTI Internal Research and Development award.

The authors wish to thank Ashley Richards for her valuable research assistance and RTI Press reviewers for helpful comments. 
RTI International is an independent, nonprofit research organization dedicated to improving the human condition by turning knowledge into practice. RTI offers innovative research and technical solutions to governments and businesses worldwide in the areas of health and pharmaceuticals, education and training, surveys and statistics, advanced technology, international development, economic and social policy, energy and the environment, and laboratory and chemistry services.

The RTI Press complements traditional publication outlets by providing another way for RTI researchers to disseminate the knowledge they generate. This PDF document is offered as a public service of RTI International. More information about RTI Press can be found at www.rti.org/rtipress. 